\title{
PROSTVAC-Contaminated W/ BVDV
}

National Cancer Institute

\section{Source}

National Cancer Institute. PROST VAC-Contaminated WI BVDV. NCI Thesaurus. Code C29334.

A vaccinia virus carrying a copy of the human gene encoding prostate-specific antigen (PSA), contaminated with bovine viral diarrhea virus (BVDV). 